\title{
Evaluation of Bone Tissue After Cafeteria-Diet-Induced Obesity and Periodontitis in Rats
}

\author{
Cassiane Merigo do Nascimento ${ }^{a}$, Francielly A. Felipettia ${ }^{\text {, Tiago }}$ Cassol $^{\mathrm{a}}$, Ana Lucia C. A. Rangel ${ }^{\mathrm{a}}$, \\ Maria Lucio Bonfleur ${ }^{\mathrm{a}}$, Sandra L. Balbo ${ }^{\mathrm{a}}$, Carlos Augusto Nassar ${ }^{\mathrm{a}}$, Patricia Oehlmeyer Nassar ${ }^{\mathrm{a}}$, b
}

\begin{abstract}
Background: The purpose of this paper was to evaluate the influence of obesity on alveolar bone tissue, either associated with ligature-induced periodontal disease, or not. The possible association between obesity and periodontitis is mainly related to the production of inflammatory cytokines.
\end{abstract}

Methods: Twenty-four male Wistar rats were divided into the following groups: control group $(\mathrm{CON})$; ligature group (LIG) with periodontitis by ligature was induced in the 24th week; obese group (OBESE) received cafeteria diet; obese and ligature group (OBESE + LIG) received cafeteria diet and periodontitis by ligature was induced in the 24th week.

Results: The number of osteocytes in the alveolar bone region and the distance from the cementoenamel junction to the alveolar crest were assessed, and descriptive analysis of tissues was performed. The results showed that both obesity and periodontitis led to decreased number of osteocytes $(\mathrm{P}<0.01)$, and increased distance from the cementoenamel junction to the alveolar crest $(\mathrm{P}<0.01)$.

Conclusions: In addition, inflammatory characteristics and bone reabsorption in the periodontal tissue were found. It could be concluded that both periodontitis and obesity, in isolation, resulted in a reduction of alveolar bone mass; however, it was more intense when associated with bone loss, demonstrating that obesity contributed to bone loss in periodontitis.

Keywords: Periodontitis; Obesity; Alveolar bone loss; Bone; Ligature; Rats

Manuscript accepted for publication November 27, 2014

aState University of Western Parana (UNIOESTE), Cascavel Campus, PR, Brazil

${ }^{b}$ Corresponding Author: Patricia Oehlmeyer Nassar, State University of Western Parana (UNIOESTE), Rua Pernambuco, 593, apto 504, Centro, 85810020, Cascavel, Parana, Brazil. Email: ponassar@yahoo.com

doi: http://dx.doi.org/10.14740/jem248w

\section{Introduction}

Obesity is one of the fastest growing diseases in the world [1], reaching epidemic proportions throughout the world $[2,3]$. According to the World Health Organization (WHO), obesity rates have doubled since 1980, affecting approximately 500 million adults in 2008. As the rate of obese persons increases, periodontal diseases have become the most common and chronic diseases in human beings, affecting $5-30 \%$ of the adult population aged $25-75$ years or older [4].

In 1977, a study conducted by Perlstein and Bissada showed that obesity contributed to the severity of periodontitis in rats [5]. Since then, many studies have assessed the relationship between obesity and periodontitis [6-8]. In 1998, Saito and colleagues [6] found that the body mass index (BMI) and increase in body fat were positively related to the prevalence of periodontitis in healthy people. According to the authors, an increase of $5 \%$ in body fat corresponds to a $30 \%$ increase in the risk of developing periodontitis [6]. Other studies have also demonstrated that the increase in BMI is associated with increasing risk of developing periodontitis [7] and increase in waist/hip ratio [9].

The possible association between periodontitis and obesity may be attributable to inflammatory cytokines that are in an altered state in obese individuals. These cytokines are capable of promoting a chronic inflammatory process in periodontitis in these patients [4]. Adipose tissue, in addition to secreting proinflammatory cytokines, may also stimulate the participation of macrophages in the pathogenic process of the disease, and thus enhance its characteristics. Therefore, the accumulation of adipose tissue would increase the probability of an inflammatory response in periodontitis [10]. The increase in the concentration of tumor necrosis factor (TNF- $\alpha$ ) and interleukin 6 (IL-6) in obesity [11] may exacerbate pre-existing periodontitis by stimulating fibroblasts that promote the synthesis of degrading enzymes and stimulate osteoclasts that activate the bone resorption [12].

Another substance that relates obesity and periodontitis is plasminogen activator inhibitor 1 (PAI-1), which is strongly expressed by visceral fat and induces agglutination of blood. Thus, PAI-1 may decrease blood flow in the periodontium and contribute to the development of periodontal disease. In addition, a high-fat or fatty acid diet may suppress bactericidal function - Porphyromonas gingivalis - of the immune system 
Table 1. Cafeteria Diet (High-Fat Diet) Composition

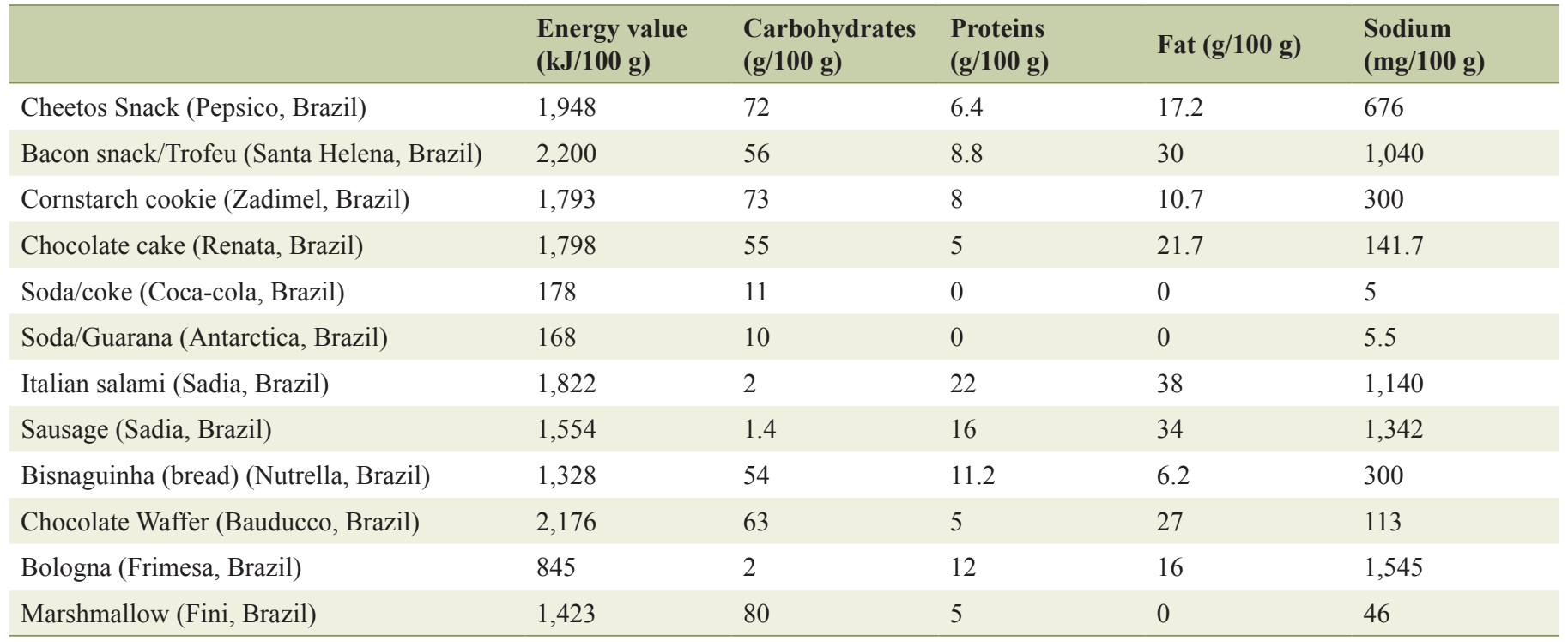

in humans, favoring the development of periodontitis [13].

Up to now, it is not clear whether periodontitis is able to affect lipid metabolism or whether the alterations in obesityrelated lipid metabolism cause the alterations in periodontal tissue [14].

Therefore, the aim of this study was to evaluate the behavior of bone tissue in rats by means of cafeteria-diet-induced obesity, either associated with ligature-induced periodontal disease, or not.

\section{Materials and Methods}

This was a descriptive, quantitative, and experimental research. The research was approved by Ethics Committee on Animal Experimentation (CEUA/UNIOESTE) UNIOESTE. To conduct this experiment, 24 8-week-old male Wistar rats were used. They were obtained at the central vivarium of UNIOESTE and kept at the Laboratory of Endocrine Physiology and Metabolism of the institution under controlled light (12-h light/dark cycle) and temperature $\left(21 \pm 2{ }^{\circ} \mathrm{C}\right)$ conditions. The animals were randomly divided into four groups: 1) control group $(\mathrm{CON})$ received a standard diet and water for 28 weeks; 2) cafeteria group (OBESE) received a high-fat diet and soda for 28 weeks; 3) ligature group (LIG) received a standard diet and water for 28 weeks and periodontal disease was induced with ligatures in 24th week of experiment; 4) obese and ligature group (OBESE + LIG) received a high-fat diet and soda for 28 weeks and periodontal disease was induced with ligatures in 24th week of experiment.

To induce obesity in the animals, the exogenous obesity model, known as the westernized diet, fast-food or cafeteria diet, was used. This model consists of the administration of a hypercaloric diet with an increased amount of fats and carbohydrates $[15,16]$. The exact composition of the diet is shown in Table 1.
The amount of each type of food offered to each animal was weighed daily to prevent any difference in the food supply among the animals.

To control the animals' weight, they were individually weighed once a week throughout the experimental period.

In the 24th week of the experiment, the rats were anesthetized by intramuscular administration of ketamine (francotar1) $(0.08 \mathrm{~mL} / 100 \mathrm{~g}$ body weight) and xylazine (virbaxil1) (Virbac do Brazil Ind. and Com. Ltda, Sao Paulo, SP, Brazil) (0.04 $\mathrm{mL} / 100 \mathrm{~g}$ body weight), and a 3.0 silk ligature was placed around each right first molar to induce periodontal disease development [17].

At the end of the 28th week of the experiment, the animals were weighed and the nasoanal length was obtained for the Lee index calculation (cube root of body weight (g)/nasoanal length (cm)). Subsequently, the animals underwent desensitization by $\mathrm{CO}_{2}$ and euthanasia by decapitation and the periepididymal and retroperitoneal fat pads were removed and weighed.

The jaws of the animals were removed and fixed in a $10 \%$ formaldehyde solution for $24 \mathrm{~h}$. After this period, they were washed under running water for $1 \mathrm{~h}$ and immersed in a formic acid solution. The pieces were kept in a decalcification solution for about 10 days. After this time interval, the pieces were washed again under running water for $1 \mathrm{~h}$ and the histological process was automatically performed for about 12 h (automatic tissue processor, Leica Microsystems ${ }^{\circledR}$ TP1020, Nussloch, Germany). After this, the samples were paraffin-embedded to obtain paraffin blocks (Purified Paraffin, code 1228, lot 1008459, Vetec Quimica Fina, Rio de Janeiro, Brazil). The blocks were cut in a semi-automatic microtome (Hestion ${ }^{\circledR}$, ERM3000, Daintree Scientific, St. Helens, Australia) into histological sections measuring $5 \mu \mathrm{m}$. The sections were mounted on slides and stained with hematoxylin and eosin.

The histological sections were evaluated by a single examiner using a transmitted light microscope (Leica Microsys- 
Table 2. Body Weight Values, Nasoanal Length and Lee Index

\begin{tabular}{llll}
\hline Groups & Final weight $(\mathrm{g})$ & Nasoanal length $(\mathbf{c m})$ & Lee index $(\mathrm{g} / \mathbf{c m})$ \\
\hline CONTROL & $472 \pm 1.0^{\mathrm{A}}$ & $24.0 \pm 1.0^{\mathrm{A}}$ & $320.7 \pm 15.0^{\mathrm{A}}$ \\
LIG & $460 \pm 2.0^{\mathrm{A}}$ & $24.0 \pm 1.0^{\mathrm{A}}$ & $316.9 \pm 10.0^{\mathrm{B}}$ \\
OBESE & $630 \pm 5.5^{\mathrm{B}}$ & $25.5 \pm 1.0^{\mathrm{AB}}$ & $336.0 \pm 13.0^{\mathrm{C}}$ \\
OBESE + LIG & $618 \pm 2.5^{\mathrm{B}}$ & $26.4 \pm 1.0^{\mathrm{B}}$ & $322.0 \pm 11.0^{\mathrm{D}}$ \\
\hline
\end{tabular}

$P<0.01$. Different letters indicate that the results are statistically different between groups, in the same parameter of evaluation. The values represent mean \pm standard deviation.

Table 3. Values of the Weights of Retroperitoneal and Periepidimal Fat With Relationship at the Total Weight in Animals

\begin{tabular}{llllll}
\hline \multirow{2}{*}{ Groups } & \multicolumn{2}{c}{ Retroperitoneal fat } & \multicolumn{2}{c}{ Periepidimal fat } \\
\cline { 2 - 3 } \cline { 5 - 6 } & Weights $(\mathrm{g})$ & Weight percentage $(\%)$ & & Weights $(\mathrm{g})$ & Weight percentage (\%) \\
\hline CONTROL & $5.8 \pm 1.0^{\mathrm{A}}$ & $1.2 \pm 0.2^{\mathrm{A}}$ & $7.4 \pm 1.4^{\mathrm{A}}$ & $1.6 \pm 0.3^{\mathrm{A}}$ \\
LIG & $6.0 \pm 1.0^{\mathrm{A}}$ & $1.3 \pm 0.2^{\mathrm{A}}$ & $7.2 \pm 1.0^{\mathrm{A}}$ & $1.6 \pm 0.2^{\mathrm{A}}$ \\
OBESE & $30.6 \pm 4.0^{\mathrm{B}}$ & $4.8 \pm 0.5^{\mathrm{B}}$ & $14.3 \pm 2.9^{\mathrm{B}}$ & $2.3 \pm 0.4^{\mathrm{B}}$ \\
OBESE + LIG & $26.0 \pm 4.0^{\mathrm{B}}$ & $4.2 \pm 0.7^{\mathrm{B}}$ & $14.4 \pm 1.8^{\mathrm{B}}$ & $2.3 \pm 0.2^{\mathrm{B}}$ \\
\hline
\end{tabular}

$P<0.01$. Different letters indicate that the results are statistically different between groups, in the same parameter of evaluation. The values represent mean \pm standard deviation.

tems, Switzerland). Histological analysis consisted of two parts: qualitative (morphology) and quantitative (morphometric). These analyses consisted of a descriptive analysis of the blades, quantification of osteocytes, and measurement of the alveolar crest height. Morphologic analysis of the parts was performed by photomicrography. Magnification depended on the need to visualize the desired structures. The following features were observed: periodontal tissue integrity, presence of inflammatory infiltration, bacterial colonies, and bone tissue characteristics. The morphometric analysis consisted of the quantification of osteocytes from five consecutive fields/areas of the alveolar bone crest starting from the highest point. The samples were viewed at $\times 100$ magnification. Two observations per field were performed on two different days.

The alveolar bone crest height was measured with the aid of a microscope coupled to a computer and the images were captured using the LazEz ${ }^{\circledR}$ software program. The shortest distance between the apex of the buccal alveolar bone crest and the cementoenamel junction was also measured. The measure-

Table 4. Average Counting - Alveolar Bone Osteocytes in Animals

\begin{tabular}{ll}
\hline Groups & Mean \\
\hline CONTROL & $51.27 \pm 1.59^{\mathrm{A}}$ \\
LIG & $45.98 \pm 1.05^{\mathrm{B}}$ \\
OBESE & $48.78 \pm 0.89^{\mathrm{C}}$ \\
OBESE + LIG & $37.24 \pm 0.90^{\mathrm{D}}$ \\
\hline
\end{tabular}

$P<0.01$. Different letters indicate that the results are statistically different between groups, in the same parameter of evaluation. The values represent mean \pm standard deviation. ments were repeated twice a day, on two different days, and a mean of the results was obtained.

The data obtained were analyzed and evaluated using the ANOVA and Tukey tests at $\mathrm{P}<0.01$.

\section{Results}

Table 2 shows the mean values of final body weight, nasoanal length, and Lee index with respect to the groups of rats.

The results significantly demonstrated that the rats subjected to the cafeteria diet had a mean increase of $32 \%$ in total body weight in the control group. Significant increases were also observed for the nasoanal length and Lee index. These results show that the diet model used was effective to induce obesity in animals.

Table 3 shows the mean values of the weights of retroperitoneal and periepidimal fat pads of animals in the four groups.

The results show that on average, there was an increase of

Table 5. Mean Values of the Distance From the Cementoenamel Junction to Alveolar Bone

\begin{tabular}{ll}
\hline Groups & Mean $(\boldsymbol{\mu m})$ \\
\hline CONTROL & $336.85 \pm 10.84^{\mathrm{A}}$ \\
LIG & $776.19 \pm 34.44^{\mathrm{B}}$ \\
OBESE & $542.29 \pm 12.84^{\mathrm{C}}$ \\
OBESE + LIG & $822.12 \pm 24.96^{\mathrm{D}}$ \\
\hline
\end{tabular}

$P<0.01$. Different letters indicate that the results are statistically different between groups, in the same parameter of evaluation. The values represent mean \pm standard deviation. 


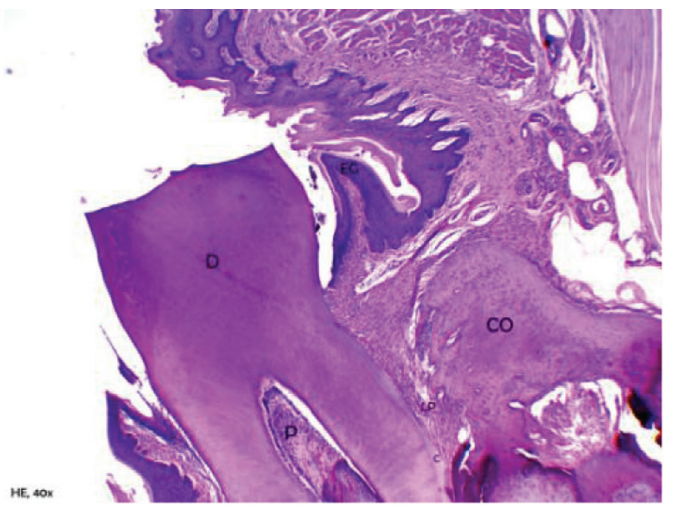

Figure 1. Representative photomicrography of an animal from control group. D: dentin; P: pulp; EG: gingival epithelium; CO: crest bone; LP: periodontal ligament; C (hematoxylin and eosin, $\times 40$ ).

$22.4 \mathrm{~g}$ in retroperitoneal fat and $7.05 \mathrm{~g}$ in periepidimal fat in the animals subjected to the cafeteria diet when compared with the control group.

Table 4 shows the average result of the number of osteocytes in the animals according to the groups. As the results show, induced-periodontal disease resulted in a $10 \%$ decrease in the number of osteocytes in the animals with induced periodontitis. This decrease was even greater when obesity was associated with periodontal disease, attaining a reduction of $27.03 \%$ in these animals. Furthermore, the results showed a decrease of $4.86 \%$ in the number of osteocytes in the obese animals, demonstrating that obesity, whether alone or combined with periodontitis, contributed to the decrease in the number of osteocytes.

Table 5 shows the mean values per group, of the distance from the cementoenamel junction to the alveolar bone crest.

When periodontal disease was present, an increase of $130.43 \%$ in the distance from the cementoenamel junction to the alveolar crest was observed, in comparison with the control group. The distance between the cementoenamel junction and the alveolar bone crest was even higher when periodontal disease was associated with obesity, corresponding to an increase of $144.06 \%$ in comparison with the control group, demonstrat-

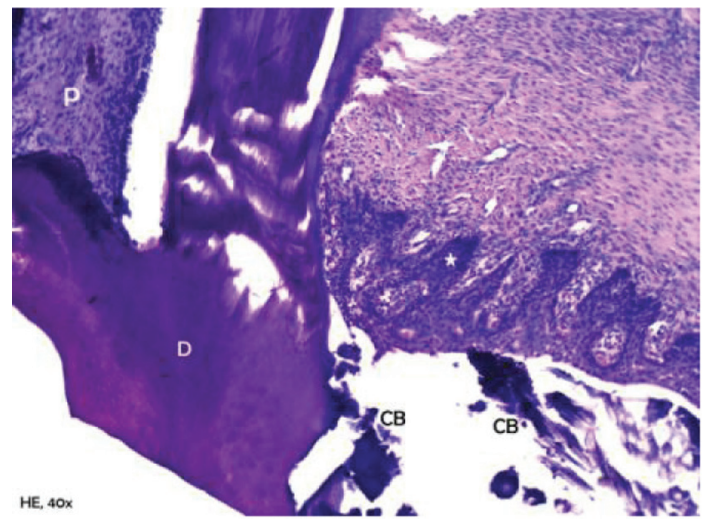

Figure 2. Representative photomicrography of an animal from the group with induced periodontal disease and gingival epithelium exocytosis $\left(^{*}\right)$ (hematoxylin and eosin, $\times 40$ ).

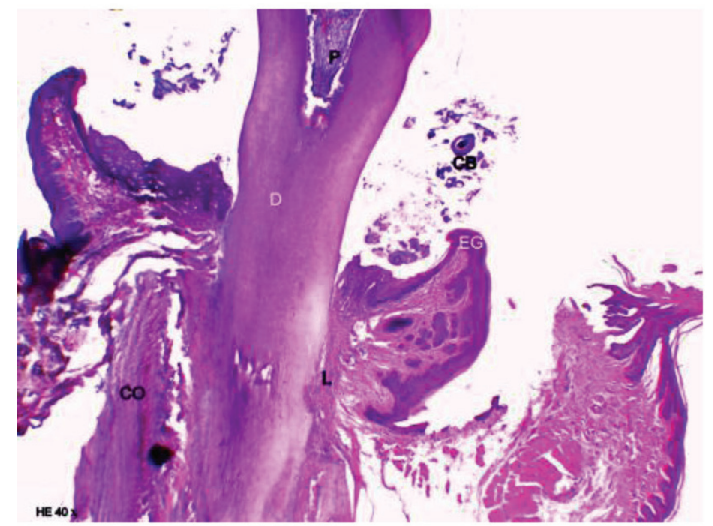

Figure 3. Representative photomicrography of an animal from the group with induced periodontal disease. D: dentin; P: pulp; CB: bacterial colonies. Exposure of the cervical third of the root (hematoxylin and eosin, $\times 40)$.

ing that the association between obesity and periodontal disease accentuates this distance.

Moreover, the distance from the cementoenamel junction to the alveolar crest increased by only $37.88 \%$ in the group induced to obesity, when compared with the control group.

\section{Descriptive morphological analysis of periodontal tissues}

Figure 1 shows a representative photograph of the control group, in which it was observed that the gingival tissue, the sulcular epithelium, the junctional epithelium and underlying connective tissue in the region of the first molar showed normal characteristics. No inflammatory process was perceived in this tissue, and in some cases only, a few bacterial colonies were observed. The alveolar bone was intact, compact and regular, with a central spongy portion of normal appearance. The bone crests were thick and high (in the cervical third of the root). No expressive osteoclastic activity was found, and the cementoenamel junction, cementum, and periodontal ligament presented normal characteristics.

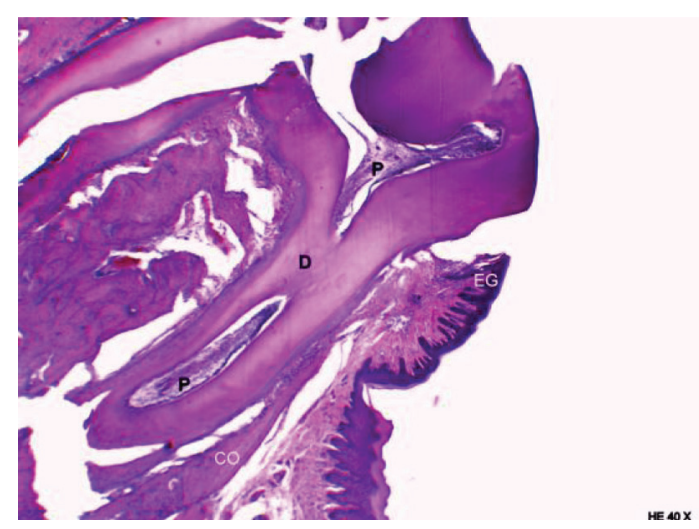

Figure 4. Representative photomicrography of an animal from group obese. D: dentin; P: pulp; CB: bacterial colonies (hematoxylin and eo$\sin , \times 40)$. 


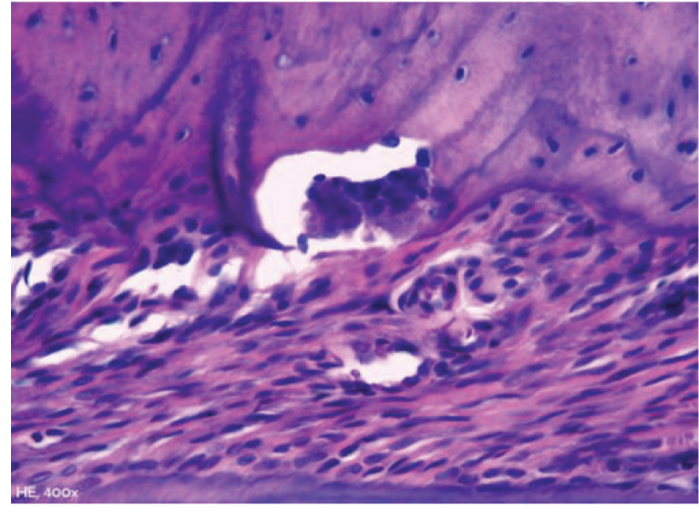

Figure 5. Representative photomicrography of bone resorption area in an animal from group obese. Howship's lacunae occupied by an osteoclast in the bone crest region (hematoxylin and eosin, $\times 400$ ).

Figure 2 shows ligature-induced periodontitis in the nonobese group of rats. For this group, the junctional epithelium presented a hyperplastic and discrete apical migration. Bacterial colonies were seen along the tooth surface. The underlying connective tissue had become extremely inflamed, with a predominance of acute inflammatory infiltration and exocytosis in the sulcular and junctional epithelium.

The alveolar process was compact, with a spongy central area, but with tapered and low bone crests, causing the exposure of the cervical third (Fig. 3). Bone neoformation was observed in the alveolar crests, shown by incremental lines in the regions of the periodontal ligament adjacent to the bone crests. Furthermore, it was found that the cementum was thickened in the apical third, suggestive of local hypercementosis.

Figure 4 shows the group in which only obesity was associated. The presence of a slight mixed inflammatory infiltration with a predominance of neutrophils was found in the underlying connective tissue, and mild exocytosis in the junctional epithelium. The alveolar process was compact, with a spongy central area, but with tapered bone crests when compared with the control group. Osteoclastic activity was observed in these areas as shown in Figure 5. Severe resorption activity was

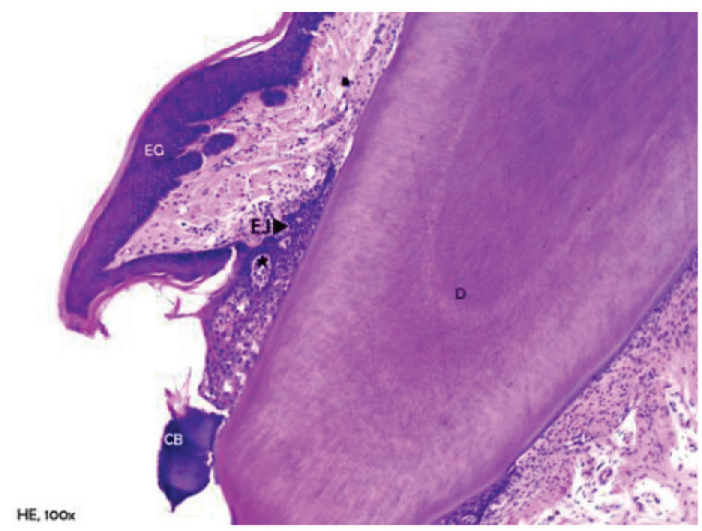

Figure 6. Representative photomicrography of an animal from the obese group with periodontal disease. D: dentin; EG: gingival epithelium; EJ: junctional epithelium; CB: bacterial colonies (hematoxylin and eosin, $\times 40)$.

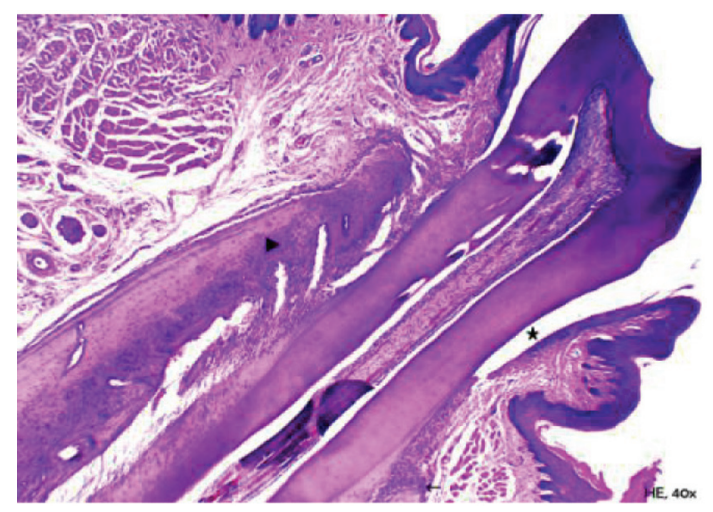

Figure 7. Representative photomicrography of an animal from the obese group with periodontal disease. Note that bone crests are tapered (arrow's head) and adjacent to the buccal root (lower right portion of the image); only the tip of the crest (arrow) is extremely low, the mean/apical level of the root (hematoxylin and eosin, $\times 40$ ).

shown in the alveolar bone and crests. The thickness of the cementum and periodontal ligament along the root dentin was normal.

Figure 6 shows the group of animals, in which periodontitis was associated with obesity. An accumulation of bacterial colonies was noted adjacent to the tooth surface, as well as migration of the gingival margin apical to the cementoenamel junction. In addition, an extension and apical migration of the junctional epithelium and the presence of mixed inflammatory infiltration was observed in the underlying connective tissue, with a predominance of lymphocytes. The alveolar process was compact, with a spongy central area, but with tapered and low bone crests when compared with the control group at the level of the middle third of the root (Fig. 7). Similarly to the obese group, bone neoformation was observed in the alveolar crests, shown by incremental lines of bone neoformation and intense activity of osteoblasts lining the regions of the periodontal ligament adjacent to the bone crests (Fig. 8). Osteoclastic activity was found in the basal bone. Furthermore, the cementum was found to be thickened in the apical third, sug-

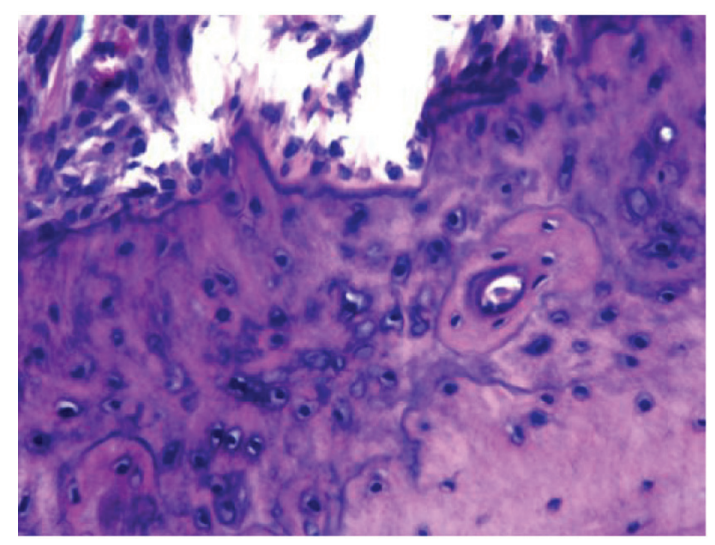

Figure 8. Representative photomicrography of bone neoformation in an animal from the obese group with periodontal disease (hematoxylin and eosin, $\times 400)$. 
gestive of local hypercementosis.

\section{Discussion}

Diet is considered the most frequent cause of obesity in industrialized and urbanized countries [18]. In the present study, it was possible to verify the effectiveness of the cafeteria diet to induce obesity. According to the data presented, when compared with the control group, the animals subjected to the cafeteria diet showed a significant increase in the weight, Lee index (Table 2) and weight of the retroperitoneal and perigonadal fat pads (Table 3 ). Similar results were obtained in other studies using similar models to induce obesity $[19,20]$.

Furthermore, concerning the retroperitoneal and periepidimal fat and final weights, it is interesting to note that, when the same protocols were compared (comparison between the $\mathrm{CON}$ and LIG groups without induced obesity and comparison between the OBESE and OBESE + LIG groups with induced obesity by cafeteria diet), there was a reduction in these parameters (final weights and fats) in groups in which periodontal disease was induced, although not statistically significant, which would suggest that the ligature, contributing to the development of periodontal disease, may have influenced the feeding behavior in the rat.

The results also showed that for the obese group not associated with periodontitis, the presence of inflammatory infiltration and resorptive activity was found, in addition to a lower number of osteocytes and greater distance from the cementoenamel junction to the alveolar bone crest, when compared with the control group.

Several studies have indicated that obesity itself is associated with a level of chronic inflammation. This inflammatory response is characterized by abnormal cytokine production, increased acute phase reactants, and inflammatory signaling pathway activation [21-24]. It has also been established that an increased production of proinflammatory cytokines contributes to the development of osteoporosis and osteopenia [25, 26]. Studies have shown that the excessive increase in body fat is associated with decreased bone mineral density [27, 28].

As regards the groups subjected to periodontitis, the results obtained show that both the non-obese group with periodontal disease and the group in which periodontitis was associated with obesity presented alterations in the junctional epithelium, presence of bacterial colonies along the tooth surface, as well as inflammatory features and osteoclastic resorptive activity. On the other hand, these characteristics were more intense in the obese group with periodontitis, which was evident from the lower number of osteocytes and greater distance from the cementoenamel junction when compared with the other groups.

Periodontitis is an inflammatory disease associated with bone resorption [26]. The increased production of proinflammatory cytokines such as IL- 1 , IL- 6 and TNF- $\alpha$ is also associated with the increase in the osteoclastic resorptive activity in several diseases, including periodontitis [25].

Several authors consider that the association between obesity and periodontal disease is plausible due to the increased concentration of proinflammatory cytokines and TNF- $\alpha$ produced by the adipose tissue of obese individuals, development of insulin resistance and a chronic inflammatory condition [5, $6,10,14,29]$. Cytokines are key mediators in the process of osteoclast differentiation and bone resorption. Chronic inflammation and the increase in inflammatory cytokines induce bone resorption and bone loss in patients with periodontitis [30].

In the study conducted by Perlstein and Bissada [5], the periodontal structure of obese animals with periodontitis was assessed. Histopathological analysis showed hypertrophy and hyperplasia of blood vessels in the periodontium of these animals. The authors concluded that obesity contributed to the severity of periodontal disease.

Obesity seems to affect bone metabolism through multiple mechanisms. First, osteoblasts and adipocytes derive from a common mesenchymal cell in the bone marrow. Obesity can induce adipogenesis while decreasing osteoblastogenesis [22]. The direct or indirect production of leptin and adiponectin related to obesity may influence bone metabolism. Circulating leptin levels are high in cases of obesity. The action of leptin on bone seems to be variable; however, it seems to negatively affect the bone metabolism of animals subjected to high-fatdiet-induced obesity [23].

Paradoxically, this study showed that in both groups with periodontal disease, obese and non-obese groups, new-bone formation was observed in the alveolar bone crests, shown by incremental lines of bone neoformation and intense activity of osteoblasts lining the regions of the periodontal ligament.

Physiologically, bone tissue adapts itself to physiological or pathological situations, and undergoes a constant remodeling process through resorption and deposition of bone matrix, processes that are strictly combined [31]. When comparing alveolar bone tissue with other bone tissues of the body, it is observed that the alveolar bone is able to undergo the remodeling process more quickly. This feature is important for promoting the positional adjustment of teeth; however, it favors the progression of periodontal disease in this tissue [32]. Thus, the presence of bone formation shown in the groups with periodontal disease may indicate a possible adaptation of the bone tissue to intense resorption that occurs as a consequence of the periodontal disease.

\section{Conclusion}

According to the results obtained in the present study, it could be concluded that both periodontal disease and obesity, alone, resulted in the reduction of alveolar bone mass, which was more intense when associated with bone loss, demonstrating that obesity contributed to bone loss in periodontitis.

\section{Acknowledgement}

The authors thank the Araucaria Foundation (process number 214/2012, Fundacao Araucaria/UNIOESTE) and CAPES for the financial support. We thank the laboratory of Endocrine Physiology and Metabolism and the Pathology Laboratory of Dental School of the Western State University of Parana. The authors are extremely grateful to Marlene Bau for the technical 
assistance.

\section{References}

1. Deitel M. Overweight and obesity worldwide now estimated to involve 1.7 billion people. Obes Surg. 2003;13(3):329-330.

2. Haenle MM, Brockmann SO, Kron M, Bertling U, Mason RA, Steinbach G, Boehm BO, et al. Overweight, physical activity, tobacco and alcohol consumption in a crosssectional random sample of German adults. BMC Public Health. 2006;6:233.

3. James PT, Rigby N, Leach R. The obesity epidemic, metabolic syndrome and future prevention strategies. Eur $\mathrm{J}$ Cardiovasc Prev Rehabil. 2004;11(1):3-8.

4. Bastos AA, Falcao CB, Pereira ALA, Pereira AFV, Alves CMC. Obesidade e doenca periodontal. Pesq Bras Odontoped Clin Integr. 2005;5:275-279 (in portuguese).

5. Perlstein MI, Bissada NF. Influence of obesity and hypertension on the severity of periodontitis in rats. Oral Surg Oral Med Oral Pathol. 1977;43(5):707-719.

6. Saito T, Shimazaki Y, Sakamoto M. Obesity and periodontitis. N Engl J Med. 1998;339(7):482-483.

7. Nishimura F, Kono T, Fujimoto C, Iwamoto Y, Murayama Y. Negative effects of chronic inflammatory periodontal disease on diabetes mellitus. J Int Acad Periodontol. 2000;2(2):49-55.

8. Saito T, Shimazaki Y, Koga T, Tsuzuki M, Ohshima A. Relationship between upper body obesity and periodontitis. J Dent Res. 2001;80(7):1631-1636.

9. Al-Zahrani MS, Bissada NF, Borawskit EA. Obesity and periodontal disease in young, middle-aged, and older adults. J Periodontol. 2003;74(5):610-615.

10. Pischon N, Heng N, Bernimoulin JP, Kleber BM, Willich SN, Pischon T. Obesity, inflammation, and periodontal disease. J Dent Res. 2007;86(5):400-409.

11. Orban Z, Remaley AT, Sampson M, Trajanoski Z, Chrousos GP. The differential effect of food intake and beta-adrenergic stimulation on adipose-derived hormones and cytokines in man. J Clin Endocrinol Metab. 1999;84(6):2126-2133.

12. Nishimura F, Iwamoto Y, Mineshiba J, Shimizu A, Soga Y, Murayama Y. Periodontal disease and diabetes mellitus: the role of tumor necrosis factor-alpha in a 2-way relationship. J Periodontol. 2003;74(1):97-102.

13. Cutler CW, Iacopino AM. Periodontal disease: links with serum lipid/ triglyceride levels? Review and new data. J Int Acad Periodontol. 2003;5(2):47-51.

14. Saito T, Shimazaki Y. Metabolic disorders related to obesity and periodontal disease. Periodontol 2000. 2007;43:254-266.

15. Cesaretti ML, Kohlmann Junior O. [Experimental mod- els of insulin resistance and obesity: lessons learned]. Arq Bras Endocrinol Metabol. 2006;50(2):190-197.

16. Von Diemen V, Trindade EN, Trindade MR. [Experimental model to induce obesity in rats]. Acta Cir Bras. 2006;21(6):425-429.

17. Nassar PO, Nassar CA, Guimaraes MR, Aquino SG, Andia DC, Muscara MN, Spolidorio DM, et al. Simvastatin therapy in cyclosporine A-induced alveolar bone loss in rats. J Periodontal Res. 2009;44(4):479-488.

18. Demigne C, Bloch-Faure M, Picard N, Sabboh H, Besson C, Remesy C, Geoffroy V, et al. Mice chronically fed a westernized experimental diet as a model of obesity, metabolic syndrome and osteoporosis. Eur J Nutr. 2006;45(5):298-306.

19. de Paula RB, da Silva AA, Hall JE. Aldosterone antagonism attenuates obesity-induced hypertension and glomerular hyperfiltration. Hypertension. 2004;43(1):41-47.

20. Kretschmer BD, Schelling P, Beier N, Liebscher C, Treutel S, Kruger N, Scholz HP, et al. Modulatory role of food, feeding regime and physical exercise on body weight and insulin resistance. Life Sci. 2005;76(14):1553-1573.

21. Wellen KE, Hotamisligil GS. Obesity-induced inflammatory changes in adipose tissue. J Clin Invest. 2003;112(12):1785-1788.

22. Zhao LJ, Jiang H, Papasian CJ, Maulik D, Drees B, Hamilton J, Deng HW. Correlation of obesity and osteoporosis: effect of fat mass on the determination of osteoporosis. J Bone Miner Res. 2008;23(1):17-29.

23. Cao JJ. Effects of obesity on bone metabolism. J Orthop Surg Res. 2011;6(30.

24. Rocha VZ, Folco EJ. Inflammatory concepts of obesity. Int J Inflam. 2011;2011:529061.

25. Mundy GR. Osteoporosis and inflammation. Nutr Rev. 2007;65(12 Pt 2):S147-151.

26. Lacativa PG, Farias ML. Osteoporosis and inflammation. Arq Bras Endocrinol Metabol. 2010;54(2):123-132.

27. Goulding A, Taylor RW, Jones IE, McAuley KA, Manning PJ, Williams SM. Overweight and obese children have low bone mass and area for their weight. Int J Obes Relat Metab Disord. 2000;24(5):627-632.

28. Pollock NK, Bernard PJ, Gutin B, Davis CL, Zhu H, Dong Y. Adolescent obesity, bone mass, and cardiometabolic risk factors. J Pediatr. 2011;158(5):727-734.

29. Genco RJ. Current view of risk factors for periodontal diseases. J Periodontol. 1996;67(10 Suppl):1041-1049.

30. Van Dyke TE, Serhan CN. Resolution of inflammation: a new paradigm for the pathogenesis of periodontal diseases. J Dent Res. 2003;82(2):82-90.

31. Andia DC, Cerri PS, Spolidorio LC. Tecido osseo: aspectos morfologicos e histofisiologicos. Rev Odontol UNESP. 2006;35:191-198 (in portuguese).

32. Sodek J, McKee MD. Molecular and cellular biology of alveolar bone. Periodontol 2000. 2000;24:99-126. 